Laboratory techniques

\title{
Detection of $T$ cells in paraffin wax embedded tissue using antibodies against a peptide sequence from the CD3 antigen
}

\author{
D Y MASON, JACQUELINE CORDELL, MARION BROWN,* G PALLESEN, $\dagger$ \\ ELISABETH RALFKIAER, $\ddagger$ J ROTHBARD, * M CRUMPTON, ${ }^{*}$ K C GATTER Nuffield \\ Department of Pathology, John Radcliffe Hospital, Headington, Oxford, *Imperial Cancer Research Fund \\ Laboratories, Lincoln's Inn Fields, London, †University Institute of Pathology, Kommunehospitalet, Aarhus, \\ Denmark, $\ddagger$ Department of Pathology, Rigshospitalet, Copenhagen, Denmark
}

SUMMARY Rabbit polyclonal antibodies were raised against a proline rich, peptide sequence, comprising 13 amino acids, in the cytoplasmic domain of the CD3 $\varepsilon$ chain. Immunoprecipitation experiments showed that this antibody preparation recognised the CD3 antigen on human $T$ lymphoblasts. The antibody stained normal $T$ cells strongly in tissue sections which had been fixed in formalin or Bouin's solution and embedded in paraffin wax. Its reactivity with $\mathrm{T}$ cell lymphoma, when evaluated on a series of 96 previously phenotyped cases, closely agreed with the results obtained on cryostat sections.

These results indicate that the specific detection of $\mathrm{T}$ cells in routinely processed tissue biopsy specimens is now technically feasible on a wide scale in diagnostic laboratories using CD3 peptides antibodies, and they also suggest that in future the use of anti-peptide antibodies may detect other lineage specific antigenic markers in paraffin wax sections.

Over the past few years several antigens associated with human $\mathrm{T}$ lymphocytes have been identified through the production of monoclonal antibodies. These markers, most of which have been characterised at both the biochemical and molecular biological level, have been widely used in the study of normal and neoplastic $T$ lymphocytes in cell suspensions and tissue sections. Monoclonal antibodies against these molecules, however, have proved unsuitable for use on routinely fixed, paraffin wax embedded tissues. Histopathologists interested in the immunocytochemical study of lymphoid tissue biopsy specimens have therefore been obliged to use monoclonal antibodies against less well defined antigenic markers to stain $T$ cells in routinely processed tissue sections. The major monoclonal antibodies of this sort are UCHL1 ${ }^{1}$ against a variant of the leucocyte common antigen ${ }^{2}$; MT1, recently shown to be directed against CD43 antigen ${ }^{34}$; and MT2, which recognises a poorly characterised antigen with reported molecular weights of 200 and 190 kilodaltons. $^{3}$

Although these reagents all react with $\mathrm{T}$ cells in

Accepted for publication 25 May 1989 routinely processed tissue sections, they suffer from the drawback of not being truly specific for this cell type - that is, the variant of the leucocyte common (CD45) antigen detected by UCHL1 is also present in some myeloid cells, B lymphocytes, and some nonhaemopoietic cells ${ }^{15}$; CD43 antigen is strongly expressed on myeloid cells and on some B cells, ${ }^{4}$ and the MT2 antigen is commonly found on neoplasms of B lymphoid origin. ${ }^{36}$

We described previously how highly specific immunocytochemical labelling of $\mathrm{T}$ cells in paraffin wax sections could be achieved using polyclonal antisera raised against purified human CD3 antigen. The strong staining of both normal and neoplastic $T$ cells in routinely processed tissue sections by these reagents suggested that some epitopes (against which monoclonal antibodies have yet to be produced) survive on the CD3 molecule following routine fixation and wax embedding and can be detected by a subpopulation of antibodies present in polyclonal anti-CD3 antisera.

This study clearly indicated the feasibility of specifically detecting $\mathrm{T}$ lymphocytes in paraffin wax embedded tissue using antibodies reactive with denaturation-resistant epitopes on the CD3 molecule. 
But this approach is not readily used on a wide scale in diagnostic laboratories because the production in large quantities of polyclonal antisera specific for CD3 presents major technical difficulties. In this paper we report how this obstacle can be overcome by raising antibodies specific for a synthetic peptide which corresponds to an amino acid sequence present in one of the chains of the CD3 antigen. These antibodies were evaluated on paraffin wax embedded biopsy specimens containing normal and neoplastic human $\mathrm{T}$ lymphocytes and shown to give reactions fully comparable with those obtained previously using the polyclonal reagent against purified CD3. The production of anti-peptide antibodies may also allow a variety of other leucocyte-associated molecules to be detected in routinely processed material.

\section{Material and methods}

\section{PEPTIDE PRODUCTION}

A sequence from the cytoplasmic domain of the CD3 epsilon chain was selected as immunogen, comprising residues 156 to 168 , as published by Gold et al..$^{8}$ This sequence is as follows:

\section{$\mathrm{NH}_{2}$-Glu-Arg-Pro-Pro-Pro-Val-Pro-Asn-Pro-Asp- Tyr-Glu-Pro-Cys-COOH}

The peptide (to which a terminal cysteine was added to permit conjugation to carrier proteins) was synthesised by solid phase techniques on an Applied Biosystems peptide synthesiser (Foster City, California) model 430A. The peptide was deprotected and cleaved from the resin before separating the peptide from the protecting groups and resin by ether extraction, followed by extraction with $10 \%$ acetic acid.' The purity of the product was at least $90 \%$, as assessed by high performance liquid chromatography using a C18 reverse phase column and amino acid analysis. The peptide was coupled to thyroglobulin and to bovine serum albumin (BSA), using succinimidyl 2-(Nmaleimido-methyl) cyclohexane-1-carboxylate, at a ratio of about 20 molecules of peptide to one molecule of carrier. ${ }^{10}$

\section{IMMUNISATION}

On four occasions two rabbits received subcutaneous injections of $200 \mu \mathrm{g}$ of the thyroglobulin peptide conjugate emulsified in Freund's complete adjuvant. Injections were made at four sites subcutaneously at intervals of two weeks. The first serum samples were obtained two weeks after the fourth immunisation.

Mice (Balb/c) were immunised with $50 \mu \mathrm{g}$ of thyroglobulin peptide conjugate emulsified in Freund's complete adjuvant on three occasions at 10 day intervals followed by a final intraperitoneal booster dose $(100 \mu \mathrm{g})$. The mice were then sacrificed, their spleens removed, and cell fusion performed with the NS1 myeloma cell line by a conventional technique, as described previously. ${ }^{11}$ Monoclonal antiCD3 production was detected by immunohistological screening of culture supernates on cryostat sections of human tonsil.

\section{AFFINITY PURIFICATION OF ANTI-PEPTIDE \\ ANTIBODY}

The CD3 peptide-BSA conjugate was dialysed against $100 \mathrm{mM}$ sodium bicarbonate ( $\mathrm{pH} 8.5)$, and $2.2 \mathrm{ml}$ of this preparation (at a protein concentration of $1.3 \mathrm{mg} /$ ml) was incubated with $0.5 \mathrm{ml}$ of $\mathrm{CNBr}$-activated Sepharose (Pharmacia) for one hour at room temperature. The percentage coupling, as judged by the fall in optical density of the supernate, was $91 \%$. The Sepharose-peptide gel was then incubated for one hour with $100 \mathrm{mM}$ ethanolamine $\mathrm{HCl}(\mathrm{pH} \mathrm{8.5)}$ and washed three times in $\mathrm{pH} 2.0$ buffer, followed by $\mathrm{pH}$ 8.0 buffer. A similar technique was used to make a Sepharose-BSA gel.

Rabbit antiserum $(1.0 \mathrm{ml})$ was mixed for 72 hours with Sepharose-BSA to remove non-specific antibodies and $0.8 \mathrm{ml}$ of supernate was then incubated with $0.5 \mathrm{ml}$ of Sepharose-BSA-peptide for two hours on ice. The Sepharose-BSA-peptide was then spun down, washed with $0.15 \mathrm{M} \mathrm{NaCl}$, buffered to $\mathrm{pH} 7 \cdot 6$, with $0.05 \mathrm{M}$ Tris-HCl (TBS), and anti-peptide antibodies eluted with $100 \mathrm{mM}$ glycine buffer (pH 2). The glycine buffer was then replaced with TBS by gel filtration, giving a final yield of $2 \cdot 1 \mathrm{mg}$ of protein.

\section{TISSUE SAMPLES}

Cryostat and routinely processed paraffin wax embedded sections were obtained from biopsy material available in the authors' departments. Most samples had been fixed in formalin by routine schedules, but a few biopsy specimens had been fixed in Bouin's solution. All cases of T cell lymphoma had been phenotyped previously in cryostat sections using monoclonal antibodies against a range of lymphoid antigens. CD3 had been detected in these cryostat section studies using the antibodies anti-Leu-4, OKT3, or UCHT1. Most cases had also been stained in paraffin wax sections using polyclonal rat anti-CD3 sera, as described previously.?

\section{IMMUNOHISTOLOGICAL STAINING}

Staining was performed by the APAAP immunoalkaline phosphatase procedure. ${ }^{1213}$ Paraffin wax embedded tissues were trypsinised for 20 minutes before staining. ${ }^{14}$ Anti-CD3 peptide antisera were used at a range of dilutions between $1 / 100$ and $1 / 400$ and affinity purified antibodies were used at a concentration of $12 \mu \mathrm{g} / \mathrm{ml}$. Incubation with antisera or affinity purified antibodies was carried out at room 
temperature for either 30-60 minutes or overnight. Sections were then washed and incubated with mouse monoclonal antibody against rabbit Ig, followed by the reagents for the APAAP technique.

\section{IMMUNOPRECIPITATION OF CD3 ANTIGEN}

Human $T$ lymphoblasts were generated from peripheral blood mononuclear cells using phytohaemagglutinin (PHA) and subjected to radioiodination and immunoprecipitation as described previously. ${ }^{15}$ Each precipitate was prepared from $10^{7}$ cells labelled by lactoperoxidase catalysed iodination with $0.2 \mathrm{mCi}$ ${ }^{125}$ I(IMS 30 Amersham International, UK) and lysed in $250 \mu \mathrm{l} 1 \%$ Nonidet P40. Purified anti-peptide antibodies $(20 \mu \mathrm{g})$ adsorbed to protein A Sepharose, or UCHT1 $(5 \mu \mathrm{g})$ directly coupled to Sepharose, were used to isolate the $\mathrm{CD} 3$ antigen. Precipitates were analysed on a $12.5 \%$ sodium dodecyl sulphate polyacrylamide gel under reducing conditions and bands were shown by autoradiography.

\section{Results}

\section{POLYCLONAL ANTI-CD3 PEPTIDE ANTIBODIES}

Immunoprecipitation Anti-peptide antibodies immunoprecipitated the $\mathrm{CD} 3$ antigen $(\gamma, \delta$, and $\varepsilon$ chains) and non-covalently associated $T$ cell receptor (fig 1 , track A) from Nonidet P40 lysates of surface iodinated $T$ lymphoblasts. The patterns shown by the antipeptide antibodies and by a well characterised CD3 monoclonal antibody UCHT1 (fig 1, track B) were identical.

Immunohistological reactions Antisera from each of the two rabbits immunised with the peptide/thyroglobulin conjugate showed selective staining of $T$ cell areas in paraffin wax embedded lymphoid tissue (fig 2). There was some background staining of other tissues, such as epithelium and smooth muscle, but this was reduced or abolished when staining was performed with the peptide specific antibodies isolated by affinity purification on the Sepharose-BSA-peptide column.

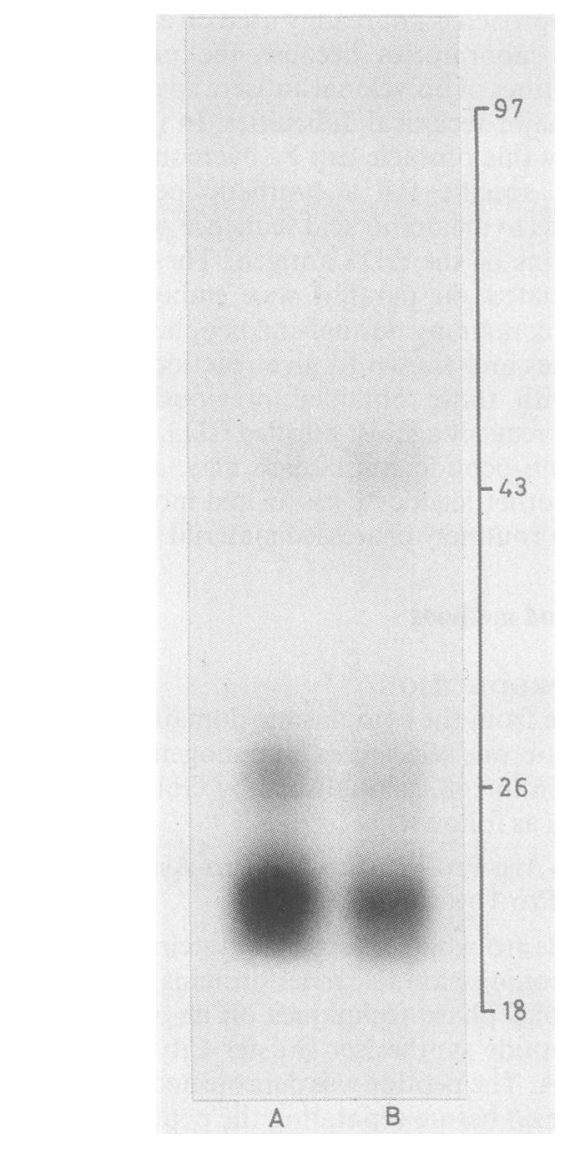

Fig $1{ }^{125}$ I Immunoprecipitates from human $T$ lymphocytes prepared with the anti-peptide antibodies (track $A$ ) and the CD3 monoclonal antibody UCHT1 (track B). Very similar precipitation patterns are seen in the two tracks, representing the $\gamma(26000), \delta(21000)$, and $\varepsilon(19000)$ chains of the $C D 3$ antigen and associated $\alpha$ and $\beta$ chains about $(45000)$ of the $T$ cell receptor. Molecular weight standards are shown on the right.

Fig 2 Normal lymphoid tissue stained with affinity purified polyclonal antibodies against CD3 peptide showing an unstained $B$ cell follicle surrounded by strongly labelled $T$ cells, viewed at $(a)$ low and $(b)$ high power. This section and the sections illustrated in figures 3-6 are all formalin fixed, paraffin wax embedded samples stained by the APAAP technique.

Fig 3 A T cell lymphoma (lymphoblastic) stained with affinity purified polyclonal antibodies against CD3 peptide, showing strong labelling of neoplastic cells, contrasting with unstained non-lymphoid cells.

Fig 4 A peripheral $T$ cell lymphoma stained with affinity purified polyclonal antibodies against CD3 peptide, showing strong labelling of neoplastic cells, surrounding a residual cluster of unstained B cells. The cleft nuclear outline of some of the neoplastic cells can be clearly seen.

Fig 5 An HTLV-I positive lymphoma showing intracytoplasmic CD3 antigen in several of the neoplastic cells (arrowed).

Fig 6 A case of lymphomatoid papulosis showing small CD3 positive lymphocytes and also large atypical cells which seem to contain intracytoplasmic CD3 (arrowed). 

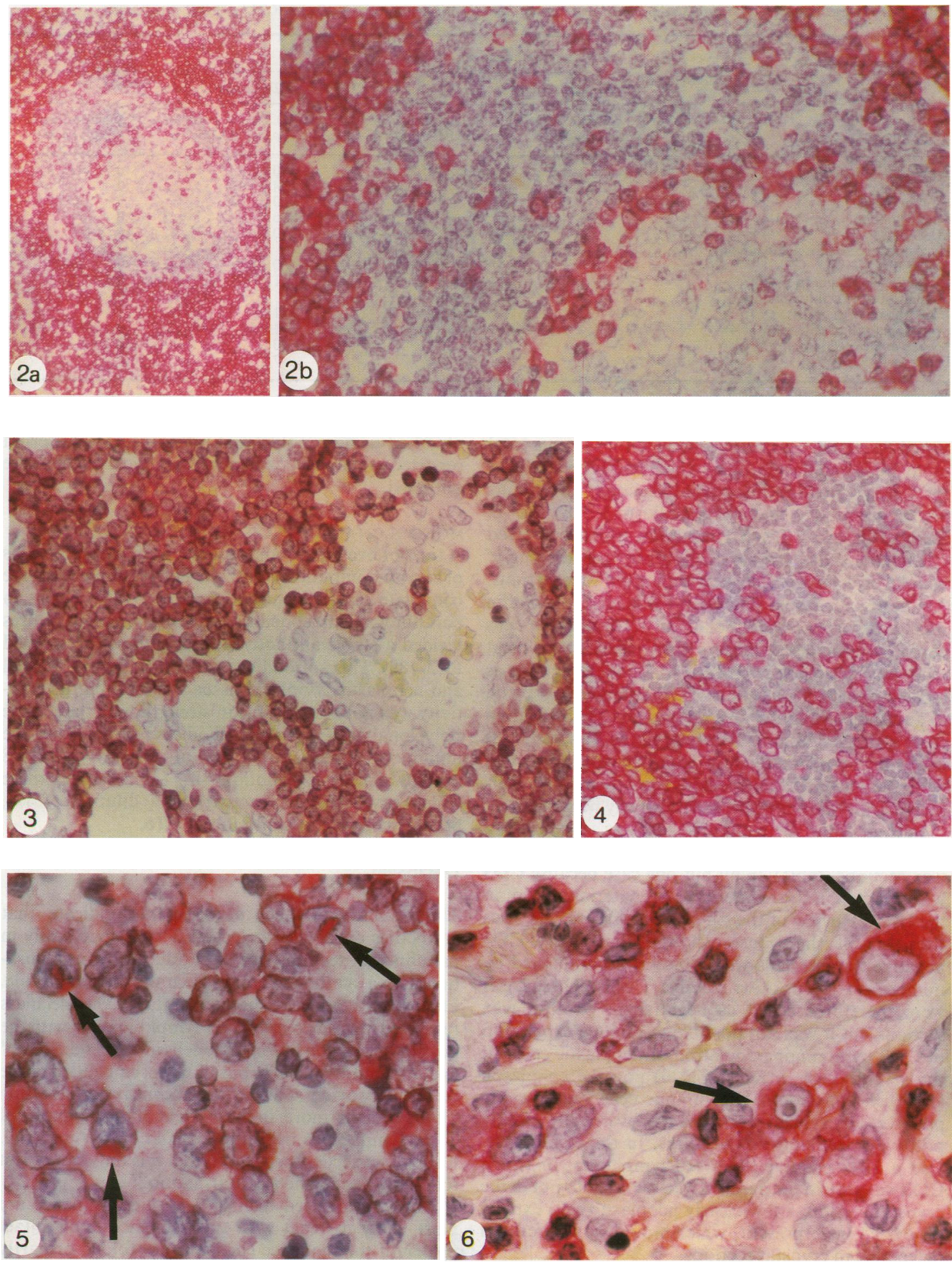
Table Immunohistological staining of paraffin wax embedded $T$ cell neoplasms with anti-CD3 peptide antibodies

The affinity purified anti-peptide antibodies were tested on paraffin wax embedded sections from a total of $96 \mathrm{~T}$ cell neoplasms, all of which had been analysed for CD3 expression in cryostat sections. The results are summarised in the table and illustrated in figs 3-6. In most cases of $\mathrm{T}$ cell lymphoma which expressed CD3 in cryostat sections, strongly positive labelling of neoplastic cells was also seen in paraffin wax sections. As the tissues tested had been embedded in paraffin wax the morphological details of CD3 positive cells could be visualised more clearly than in cryostat sections. This made it possible to see features such as intracytoplasmic inclusions of CD3 antigen (figs 5 and 6) and the perinuclear distribution of CD3 antigen in cases of $\mathrm{T}$ cell lymphoblastic lymphoma. In some cases it was also possible to show heterogeneous reactivity with the anti-CD3 antibodies, some neoplastic cells being clearly positive and others clearly negative.

In eight of the 96 neoplasms there was a discrepancy between the staining results on cryostat and paraffin wax sections (table), in all but one case because CD3 was detected in the former type of material but not in the latter. Review of the stained paraffin wax sections from six of these cases showed that many CD3 negative tumour cells were present, accompanied by numerous CD3 positive reactive $T$ cells. These cases were therefore scored as negative in paraffin wax sections but it was not possible to exclude expression of CD3 by a minor population of neoplastic cells. In the seventh case, a Ki-1 (CD30) positive anaplastic large cell lymphoma, the tumour cells were weakly positive in cryostat sections but were not clearly positive in paraffin wax sections. In the eighth case, also a $\mathrm{Ki}-1$ positive large cell lymphoma, in which CD3 was seen in the paraffin wax section but not in the cryostat section, a few clearly neoplastic cells expressing CD3 were present, which would not have been detectable in cryostat sections.
When the staining results were compared with those obtained using a polyclonal rat anti-CD3 antiserum reported previously, ${ }^{11}$ essentially identical results were obtained.

MONOCLONAL ANTI-CD3 PEPTIDE ANTIBODIES A total of five hybridoma cultures from the spleen cells of two mice immunised with the thyroglobulin/peptide conjugate secreted antibody reactive with $T$ cells in paraffin wax embedded tissues. One of these cultures yielded a stable antibody secreting clone (designated PC3/188). This antibody was tested on several normal and neoplastic lymphoid tissue samples, but its reactivity was not comparable in strength with that of the polyclonal anti-peptide antibodies. Furthermore, the immunocytochemical activity of antibody PC $3 / 188$ was rapidly lost on dilution-for example, supernate which gave optimal reactivity at a dilution of $1 / 4$, became negative at a dilution of $1 / 16$.

\section{Discussion}

The results presented in this paper indicate that antibodies capable of detecting $T$ cells specifically in paraffin wax sections can be produced by immunisation with a synthetic peptide from the CD3 molecule. Extensive studies have shown that the CD3 molecule is restricted in its expression to T lymphoid cells, with the possible exception of Purkinje cells in the cerebellum, ${ }^{16}$ and its demonstration in paraffin wax embedded tissue therefore provides a highly specific means of detecting $T$ cells. Furthermore, in the context of the diagnosis of $T$ cell lymphomas in routinely fixed biopsy material, CD3 is an excellent marker in that it is only rarely lost following neoplastic transformation. ${ }^{17}$

Antibodies raised against a peptide sequence are most likely to react with this sequence in an intact protein if the sequence chosen is not folded or partly 
buried in the native state. In the present study the peptide sequence used for immunisation was selected on the basis of a relatively high proline content (five out of 11 sequential residues), because proline is not found in $\alpha$-helices or $\beta$-sheets. A further criterion in choosing the sequence was that it occurs in the cytoplasmic domain of the CD3 $\varepsilon$ chain, a region of the molecule free of sugar residues which might cause epitope masking. Further experiments involving the immunohistological analysis of antisera raised against peptide sequences from other leucocyte-associated molecules are required, however, to assess to what degree the results obtained in the present study reflect the judicious choice of sequence.

The immunohistological staining reactions of the anti-CD3 peptide antibody on paraffin wax embedded normal lymphoid tissue were indistinguishable in their distribution from those obtained using pan-T cell antibodies (anti-CD2, anti-CD3) on cryostat sections. Hence the antibody seemed to be broadly reactive with CD3 in T cells in paraffin wax embedded tissue. A more stringent test of the specificity of the antibody was provided by staining a large series ( 96 cases) of $T$ cell lymphomas. This showed very good correlation between cryostat and paraffin wax section staining, with only eight exceptions, in all but one of which there was positivity in cryostat sections but not in paraffin wax sections. At least one of these discrepancies was probably due to the slightly lower sensitivity of the paraffin wax staining technique, because CD3 staining on the tumour cells in cryostat sections was weak and probably at a level too low for detection after fixation and embedding. This explanation may also account for the other discrepant cases in which there was the same disagreement between cryostat and paraffin wax section staining. The subjective problems inherent in assessing antigen expression in tissue sections should also be considered. All of the discrepant cases contained many reactive $T$ cells, and these may in some instances have been misinterpreted in cryostat sections as CD3 positive neoplastic cells; the better morphological preservation of paraffin wax sections allowed them to be classified as reactive.

The one case in which CD3 positive neoplastic cells could be detected in paraffin wax embedded tissue but not in cryostat sections also illustrated the benefit of the better morphological preservation seen in the former type of preparation. This case showed pronounced heterogeneity of $\mathrm{CD} 3$ expression, with just a few clearly neoplastic cells (which would not be clearly identifiable as neoplastic in cryostat sections) expressing this marker. Whatever the explanation of these rare discrepancies, the close overall correlation between cryostat and paraffin wax section staining indicates that the anti-peptide antibody offers a reliable means of detecting $\mathrm{CD} 3$ positive $T$ cell lymphomas in routinely processed tissue.

The monoclonal anti-CD3 peptide antibody PC3/ 188 gave similar reactions to the polyclonal antibodies raised against this antigen, but its reactivity was weaker. It should be possible to produce better monoclonal CD3 antibodies by immunisation with the peptide sequence, although this may be unnecessary, given the good results obtained using affinity purified polyclonal antibodies.

It will also be of interest in the future to see whether antibodies capable of detecting other leucocyteassociated antigens in paraffin wax embedded tissue can be produced by the strategy of immunising with peptide sequences. Genes encoding most leucocyte antigens defined in the CD classification system have now been cloned and sequenced so that this approach is applicable to many cell markers. Immunisation with a peptide sequence from a defined molecule is clearly preferable to the screening of randomly produced monoclonal anti-leucocyte antibodies for reactivity with paraffin wax embedded tissue, because antibodies produced by this latter approach are rarely specific for white cell populations. In contrast, immunisation with a peptide sequence from a molecule (such as CD3) which is known, as a result of extensive immunological studies, to be restricted to a single cell type, offers a much higher probability of producing lineage specific antibodies. Molecules of comparable lineage specificity exist in the case of $\mathbf{B}$ cells and myeloid cells, and we are currently exploring the efficacy of anti-peptide antibodies for the detection of these other white cell types in paraffin wax embedded tissues.

We are grateful to Margaret Jones for expertly performing the immunohistological analysis reported in this study. This project was supported in part by a grant from the Leukaemia Research Fund. KCG is a Wellcome Trust Senior Research Fellow in Clinical Science.

\section{References}

1 Norton AJ, Ramsay AD, Smith SH, et al. Monoclonal antibody (UCHL1) that recognises normal and neoplastic $T$ cells in routinely fixed tissues. J Clin Pathol 1986;39:399-405.

2 Pulido R, Cebrian M, Acevedo A, et al. Comparative biochemical and tissue distribution study of four distinct CD45 antigen specificities. J Immunol 1988;140:3851-7.

3 Poppema S, Hollema H, Visser L, Vos H. Monoclonal antibodies (MT1, MT2, MB1, MB2, MB3 reactive with leucocyte subsets in paraffin-embedded tissue sections. Am J Pathol 1987; 127:418-29.

4 Stross WP, Warnke RA, Flavell DJ, et al. Molecule detected in formalin fixed tissue by antibodies MT1, DF-T1, and L60 (Leu 22) corresponds to CD43 antigen. J Clin Pathol 1989;42:953-61.

5 Hall PA, D'Ardenne AJ, Butler MG, et al. New marker of B lymphocytes, MB2, comparison with other lymphocyte subset markers active in conventionally processed tissue sections. J Clin Pathol 1987;40:151-7. 
6 Myskow MW, Krajewski AS, Salter DM, et al. Paraffin section immunophenotyping of non-Hodgkin's lymphoma, using a panel of monoclonal antibodies. Am J Clin Pathol 1988;90: $564-74$

7 Mason DY, Krissansen GW, Davey FR, et al. Antisera against epitopes resistant to denaturation on T3 (CD3) antigen can detect reactive and neoplastic $T$ cells in paraffin embedded tissue biopsies. J Clin Pathol 1988;41:121-7.

8 Gold DP, Puck JM, Pettey CL, et al. Isolation of cDNA clones encoding the $20 \mathrm{~K}$ non-glycosylated polypeptide chain of human T-cell receptor/T3 complex. Nature 1984;321:431-4.

9 Rothbard JB, Lechler RI, Howland K et al. Structural model of HLA-DR1 restricted T cell antigen recognition. Cell 1988; 52:515-23.

10 Rothbard JB, Fernandez R, Schoolnik GK. Strain-specific and common peptides of gonococcal pili. J Exp Med 1984;160: 208-21.

11 Mason DY, Cordell JL, Pulford KAF. Production of monoclonal antibodies for immunocytochemical use. In Bullock GR and Petrusz P, eds. Techniques in immunocytochemistry. Vol 2. London: Academic Press, 1983:175-216.

12 Cordell JL, Falini B, Erber WN et al. Immunoenzymatic labelling of monoclonal antibodies using immune complexes of alkaline phosphatase and monoclonal anti-alkaline phosphatase (APAAP complexes). J Histochem Cytochem 1984;32:219-29.

13 Mason DY. Immunocytochemical labelling of monoclonal antibodies by the APAAP immunoalkaline phosphatase tech nique. In: Bullock G, Petrusz P, eds. Techniques in immunocytochemistry. Vol 3. London: Academic Press, 1985:25-42.

14 Mepham BL, Frater W, Mitchell BS. The use of proteolytic enzymes to improve immunoglobulin staining by the PAP technique. Histochem J 1979;11:345-57.

15 Brown MH, Sewell WA, Mason DY, Rothbard JB, Crumpton MJ. Species conservation of the T cell lymphocyte CD2 cell surface antigen. Eur J Immunol 1988;18:1223-7.

16 Garson JA, Beverley PCL, Coakham HB, Harper EI. Monoclonal antibodies against human $T$ lymphocytes label Purkinje neurones of many species. Nature 1982;298:375-7.

17 Hastrup N, Ralfkiaer E, Pallesen G. Aberrant phenotypes in peripheral T cell lymphomas. J Clin Pathol 1989;42:398-402.

Requests for reprints to: Dr D Y Mason, Haematology Department, John Radcliffe Hospital, Oxford OX3 9DU, England. 